Journal of Zhejiang University-SCIENCE B (Biomedicine \& Biotechnology)

ISSN 1673-1581 (Print); ISSN 1862-1783 (Online)

www.jzus.zju.edu.cn; www.springerlink.com

E-mail: jzus@zju.edu.cn

\title{
Erratum:
}

\section{Erratum to: Catalpol ameliorates LPS-induced endometritis by inhibiting inflammation and TLR4/NF-אB signaling}

\author{
Hua ZHANG ${ }^{1,2}$, Zhi-min WU ${ }^{1}$, Ya-ping YANG ${ }^{1}$, Aftab SHAUKAT ${ }^{1}$, Jing YANG $^{1}$, Ying-fang GUO ${ }^{1}$, \\ Tao ZHANG ${ }^{1}$, Xin-ying ZHU ${ }^{1}$, Jin-xia QIU ${ }^{1}$, Gan-zhen DENG ${ }^{\dagger 1}$, Dong-mei SHI ${ }^{\dagger 2}$ \\ ${ }^{1}$ Department of Clinical Veterinary Medicine, College of Veterinary Medicine, Huazhong Agricultural University, Wuhan 430070, China \\ ${ }^{2}$ Department of Veterinary Medicine, Henan University of Animal Husbandry and Economy, Zhengzhou 450046, China \\ †E-mail: ganzhendeng@sohu.com; dongmeishi126@126.com
}

https://doi.org/10.1631/jzus.B19e0071

\section{Erratum to: J Zhejiang Univ-Sci B (Biomed \& Biotechnol) 2019 20(10):816-827 https://doi.org/10.1631/jzus.B1900071}

The original version of this article unfortunately contained a mistake. In p.823, Figs. 8c and $8 \mathrm{~d}$ were incorrect, and the obvious pathological changes were mistakenly placed in the picture. The correct versions should be as follows:
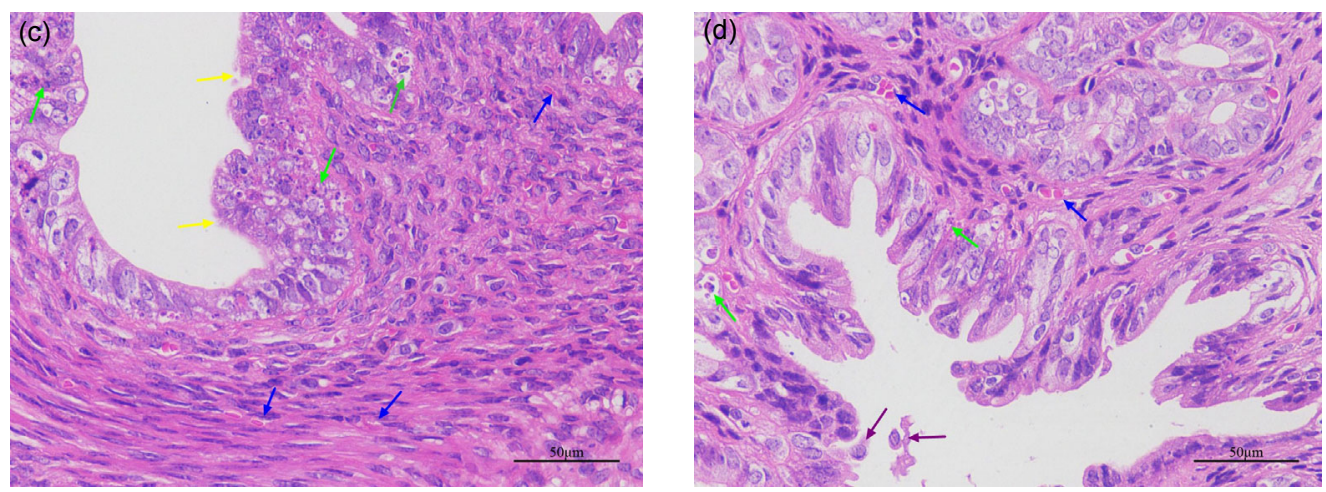

\footnotetext{
The online version of the original article can be found at https://oi.org/10.1631/jzus.B1900071

¿Corresponding authors

(C) Zhejiang University and Springer-Verlag GmbH Germany, part of Springer Nature 2019
} 